\title{
Analysis and Aesearch of White Spot on Creepage Discharge in oil- Pressboard Interface
}

\author{
YU Wen-bo ${ }^{1}$, ZHOU Xiao-xu ${ }^{2}$, CHEN Fang-dong ${ }^{1}$, CHEN Hua $^{1}$, SHANG Donghui ${ }^{1}$, HAN Xu ${ }^{1}$ \\ ${ }^{1}$ State Grid Jibei Electricity Power Maintenance Company, Beijing \\ ${ }^{2}$ BeiJing Power Equipment Group co.,LTD., Beijing
}

\begin{abstract}
Creepage discharges on oil impregnated pressboard is one of the most dangerous transformer insulation fault, which can cause the gas action even transformer housing cracking accident. "White spot" is creepage important phenomena in the process of insulation board along the surface, so it is necessary to study the insulation board along the surface of creepage "white spot" in the process of growth characteristics. This paper set up a insulating paper along the surface of creepage "white spot" in the process of growth characteristics of observation platform. Numerical example was calculated under different aging degree creepage cardboard along the surface of the "white spot" in the process of change, statistics and analysis of the "white spot" length, angle and size variation, which is very practical to the production practice.
\end{abstract}

\section{Introduction}

The oil paper insulation system is a commonly method used in the large transformer, many failure of high voltage transformer is due to the solid insulation oil (folding screen, stay, cardboard, etc.) is caused by the creeping discharge in china in recent years, so it is necessary to research the creeping discharge characteristics of aging under the different condition of the paper. Creeping discharge insulation board will form a "white spot", its essence is the discharge energy of oil gas inside the insulation board caused by decomposition and escape the cardboard, which belongs to a kind of insulation defects of recoverable. ${ }^{[1-6]}$ "White spot" is creeping discharge electric breakdown of precursors, the direction and speed of growth is directly related to the remaining life of insulation board. This paper studied the growth of the "white spot" characteristics based on the different experimental conditions..$^{[7-12]}$

\section{White spot experiment method}

It's has been more than 20 years of research work abroad in partial discharge degradation mechanism and development process of insulating materials, which is very deep especially in the research in the field of solid insulation bubble discharge, and a lot of achievements have been made.
However, most studies focus on discharge types of pattern recognition, creeping discharge development process on the surface of the paper's research is less in creeping discharge in oil paper insulation structure. It is the reason that mainly oil paper insulation belong to solid liquid two phase insulation system, what's more, the phenomenon of partial discharge is far more complicated than the simple gas discharge and solid discharge, so it is very hard for microscopic observation. Border discharge insulation board caused by the second breakdown as shown in figure 1 , the opposite has a similar situation.

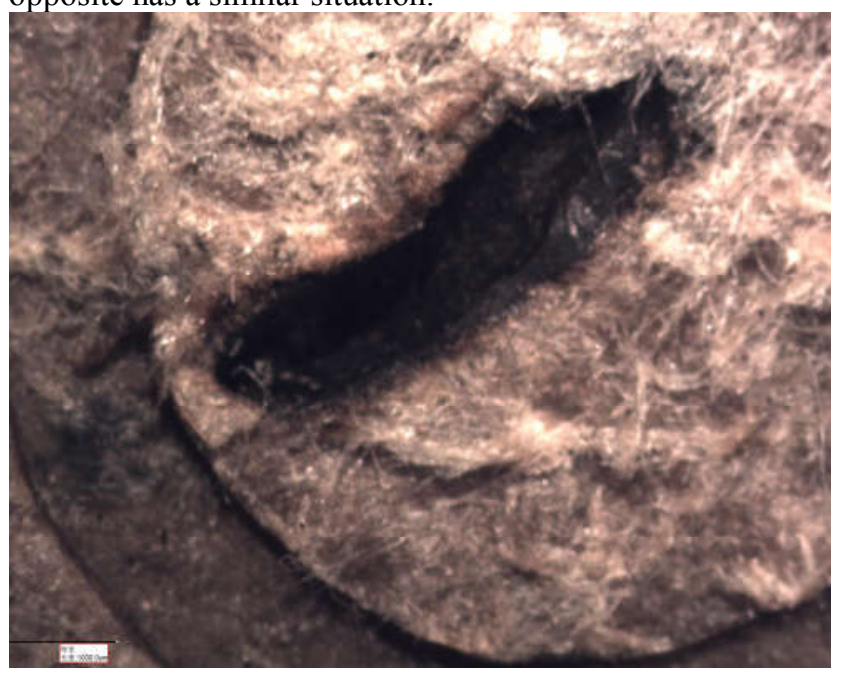

Fig. 1 The second floor positive 
White spot is the produce of the oil discharge procedure in the board, then the bubble squeeze up cardboard surface. Therefore, we can observe the cardboard white spot of the bubble as a characterization of the location and scope of important indicators of growth status. Cardboard surface bubbles produced by creepage angle and creepage length can be as a characterization of the range and position of the white spot growth, as shown in figure 2 .

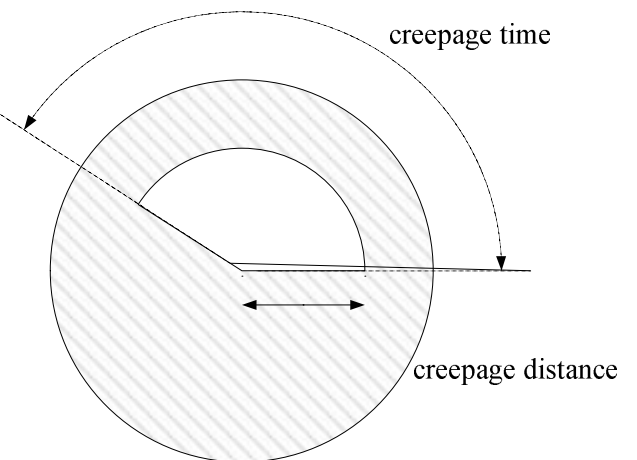

Fig. 2 White spot growth range and position

Where the creepage length calculation formula is $\mathrm{R}=\mathrm{L} / \mathrm{D} * 80(\mathrm{~mm})$, the most distant visible bubble cluster for the pick up point. Climbing angle just directly through measurement tools available for $\beta$. When there are multiple creepage points, white spots and a multiple white spots.

\section{White spot analysis of the specific conditions}

\subsection{Change tendency of creepage area}

Through real-time observation, the boards are divided into $\mathrm{A}, \mathrm{B}, \mathrm{C}$ three levels according to the degree of aging(A cardboard equal new transformer pressboard, B cardboard equal aged 10 years in transformer pressboard, B cardboard equal aged 20 years in transformer pressboard). According to the data of forensics can draw the trend chart cardboard creepage areas and surface creepage length trend chart.

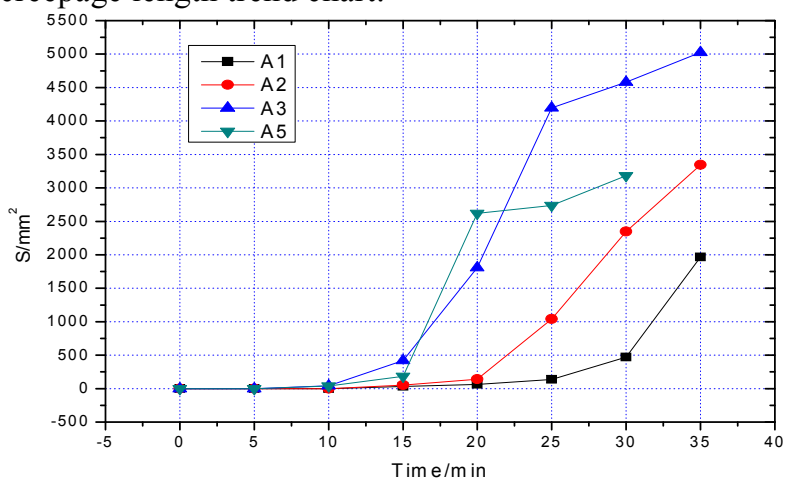

Fig 3. Group A creepage area $S_{A}$ change tendency

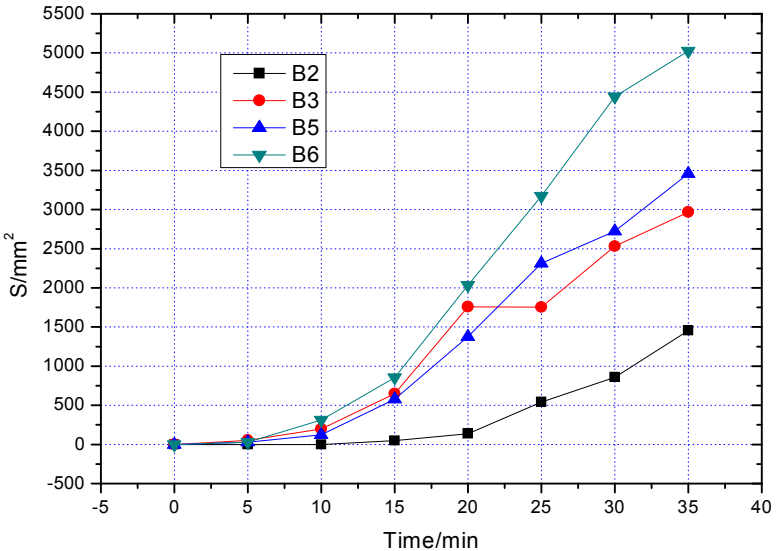

Fig 4. Group B creepage area $S_{B}$ change tendency

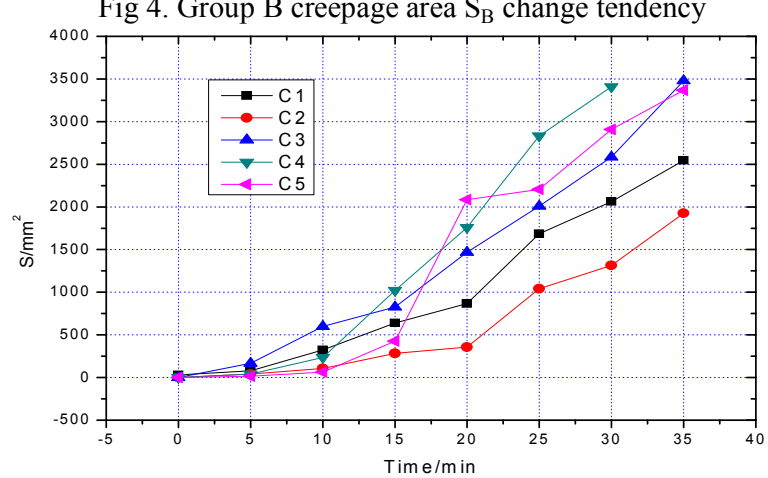

Fig 5. Group $\mathrm{C}$ creepage area $\mathrm{S}_{\mathrm{C}}$ change tendency We can find that creepage area in different aging board change trend varies greatly, cardboard in group A did not appear obvious 10 minutes before discharge, there is a sudden increase of process 15 minutes later, however, the old board in the discharge of 5 minutes will be in the cardboard surface showing clear bubble clusters. Aging board white spot is more smooth growth through the creepage area change tendency, what's more, there is a growing trend. Growth trends of the group $\mathrm{C}$ cardboard smoother than group $\mathrm{B}$, the creepage area is larger than group B at the same time.

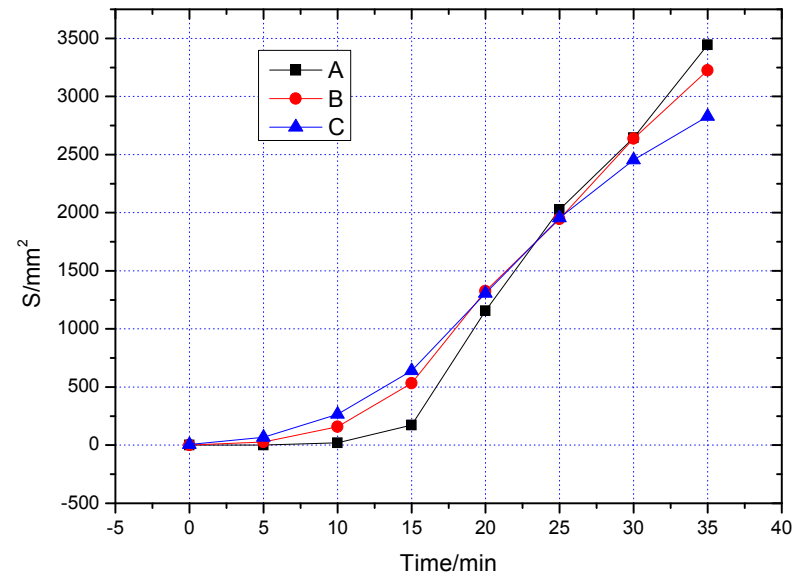

Fig 6. Groups A, B, C average cardboard creepage area $\mathrm{S}_{\text {ave }}$ change trend 
The process continuous discharge for 20 minutes after beginning to discharge, the different aging conditions in paperboards showed different growth characteristics of white spots in white spots growth process. White spot of group $\mathrm{C}$ in turn grow faster than $\mathrm{B}, \mathrm{A}$ cardboard. The trend can be seen from the the creepage area $S_{a v e}$ trends figure.

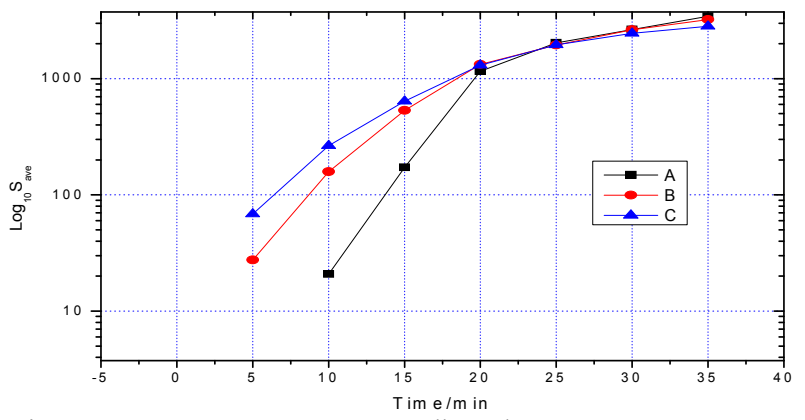

Fig 7. Groups A, B, C average cardboard creepage area $\log _{10} S_{\text {ave }}$ change trend

\subsection{Trends of Creepage lengths}

$\log _{10} \mathrm{~S}_{\text {ave }}$ trend figure is more intuitive description of the characteristics, but in late creepage, it continues 20 minutes until the breakdown of the process, the different aging conditions cardboard creepage area does not reflect the significant contrast changes. Cardboard along the creepage length $\mathrm{R}$ of the trend shown in Figure 8.

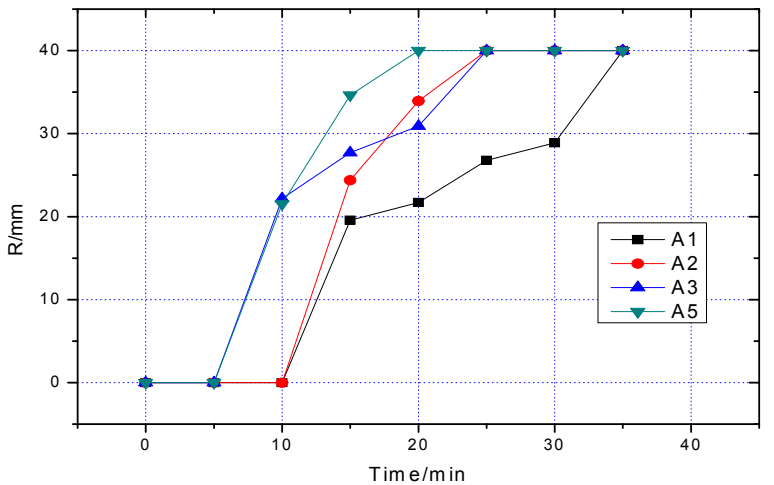

Fig 8. Group A creepage length $\mathrm{R}_{\mathrm{A}}$ change trend

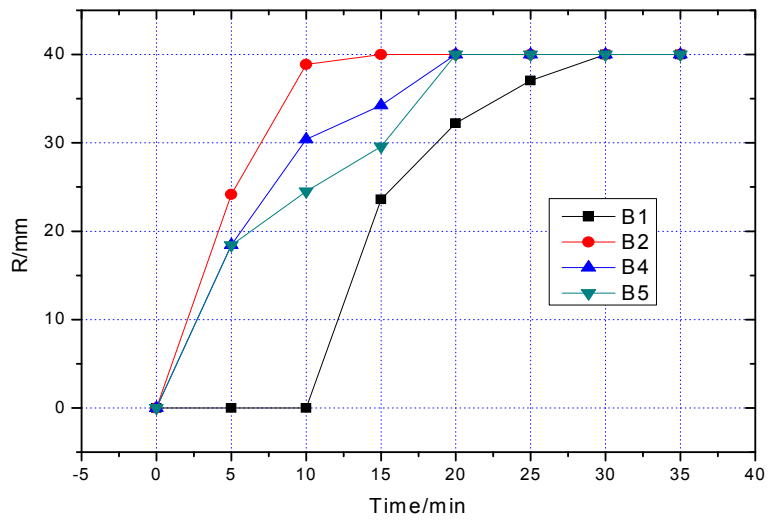

Fig 9. Group $B$ creepage length $R_{B}$ change trend

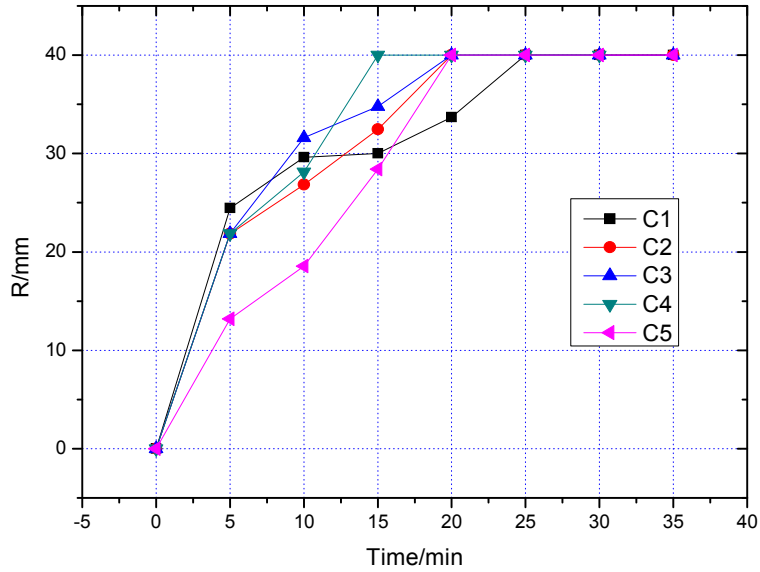

Fig 10. Group $C$ creepage length $R_{C}$ change trend From the creepage length $\mathrm{R}$ in different aging board change trend, group A cardboard can be found in the discharge there was no obvious bubble cluster before 5 minute, creepage length is approximately equal to zero. It will gradually appear in cardboard surface of creepage and grow step by step after 5-10 minutes, however, aging board discharge appears in cardboard surface creepage sust as long as five minutes, we could calculate the creepage distance. From the point of creepage time, only A cardboard group stopped growing creepage distance after 20 minutes, but there are still a set of group B and C cardboard creepage distance is growing. Compared cardboard A with cardboard B and C, cardboard A creepage distance begin to grow later, creepage distance over the growth of the time is late, too. Compared with the aging cardboard, the non-aging one creepage needs more time.

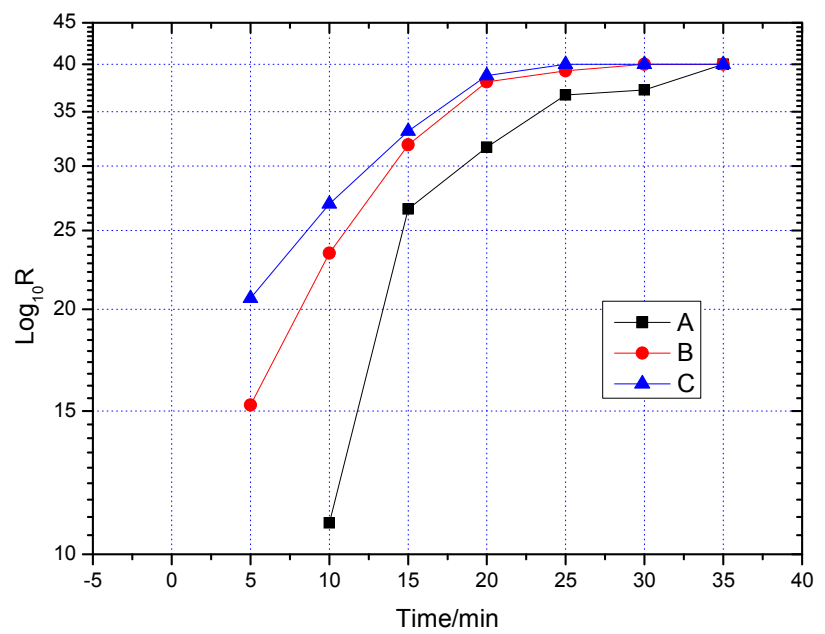

Fig 11. Trend of creepage length average $\mathrm{R}_{\mathrm{ave}}$ of the group A, B, C Board $\log _{10} R_{\text {ave }}$

As we can see that A, B, C three sets of cardboard increase the creepage distance in turn before 30 minutes, and board $\mathrm{B}$ and $\mathrm{C}$ have longer creepage distance than board $\mathrm{A}$. However, the difference is not very obvious although $\mathrm{C}$ 
cardboard longer than B cardboard between 15 minutes and 30 minutes.

\section{The law of development and comparative analysis}

There is the detailed analysis and the final creepage length (breakdown) contrast by using comparison for three groups of cardboard surface creepage development law. The paper compared three groups of cardboard through specific example in 5 minutes, 25 minutes and 35 minutes of bubble cluster development respectively .

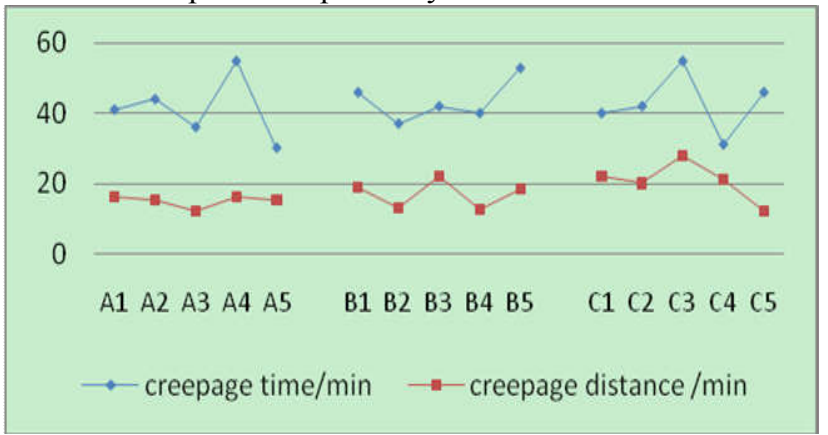

Fig 12. Creepage time and creepage length along the creepage in different cardboard

The intuitive characteristics is illustrated in figure 12 trend diagram. Three sets of cardboard creepage time averages about 43 minutes, but the final breakdown point of creepage length from $\mathrm{A}$ to $\mathrm{C}$ in turn increases at the same time.

\section{The law of development comparative analysis}

Creeping discharge development process can be divided into early discharge in the preliminary formation of white spot, early electrical branch of creepage, cardboard internal branch to further expand and electrical breakdown of the branches along the longitudinal electric field from maintaining a constant voltage to test product breakdown. In the process of preliminary white spot formation of early discharge, the oil within the board will gasify that is caused by high-energy flash discharge and then squeeze the cardboard. The obvious white spot and bubbles will appear in the cardboard surface near the high field strength, but the white spot area and the bubble cluster is relatively small at this point. The formation of white spot has a certain degree of damage on the board which encourages further discharget. The discharge will gradually develop from the surface of the slide flash into cardboard inside, it will form the initial electrical branch in strong magnetic field area of the cardboard lining, that is horizontal and vertical carbonization depth on the cardboard. The carbide prompted further extension of high field strength horizontally due to the formation of the channe, then lead to surface discharge further development. Electrical branch in the inner cardboard gradually extend, which Lead to discharge process of gas increase gradually. Bubbles on the surface of the cardboard cluster area expand step by step that discharge dense and intense. Longitudinal breakdown on board is in effect at the same time with the development of electrical branches of lateral extension to a certain degree. There will be breakdown at the forefront of electrical branches creepage points when longitudinal penetration reaches a certain critical worth time.

In the paper we can see that the aging of the cardboard with lower polymerization degree by comparring different aging time of creeping discharge process of cardboard, the gas overflow from inside the board easily when the discharge process produce a large number of bubbles.

\section{REFERENCES}

[1] A ATTEN P, SAKER A. Streamer propagation over a liquid/solid interface. IEEE Trans on Electrical In-sulation, 1993, 28(2),230-242.

[2] Barry H. Ward.A survey of new techniques in insulation monitoring of power transformers. IEEE Electrieal Insulation Magazine, 2001, 17(3): $16-23$

[3] M. D. Judd, B. M. pryor, S. C. Kelly and B.F.Hampton. Transformer Monitoring Using The UHF Technique. IEE Conference on High Voltage Engineering. London. 1999:362-365

[4] R.Schifani, R. Candela. A New Algorithm for Mixed Weibull Analysis of partial Diseharge AmPlitude Distributions IEEE Trans On Dieleetrics and Eleetrical Insulation 1999 Vo1.6 No. 2 242-249

[5] A. S. Alghamdi and S. J. Dodd. The Influence of Absothed Moisture on PartialDischarge Pattems Measured During Tree Growth in an Epoxy Resin.2007Intemational Conference on Solid Dieleetries, Winchester, UK, Julys 8-13, 2007. P623-626

[6] J. V. Champion, S .J. Dodd, A. S. Vaughan, Y. zhao and S. .J.Sutton. The Effeet of Voltage, TemPerture And Morphology On Electrical Treeing In Polyethylene Blends .Dielectric Materials, Measurements and APPlications Conference Publieation No.473, IEEE 2000. P35-40

[7] DuY, Zahn M, Lesieutre B C,eta1.Moisture equilibrium intransformer paper-oil systems[J]. Electrical Insulation Magazine,1999,15(1):11-20.

[8] Mitchinson P M, Lewin P L, Chen G, et a1.. A new approach to the study of surface discharge on the oil-pressboard interface [C]//IEEE International Conference on Dielectric Liquids. Chasseneuil, France: IEEE. 2008.

[9] Dai J, Wang Z D, Jarman P. Creepage discharge on insulation barriers in aged power transformers[J]. IEEE Transactions Oil Dieletrics and Electrical Insulation, 2010, 17(4): 1327-1335.

[10]Pahlavanpour P, Eklund, Martins M A. Insulating paper ageing and furfural formation[C]. 2003 Electrical Insulation Conference and Electrical Manufacturing \& Coil Winding Technology Conference Proceedings. Toronto, 2003: 283-28

[11]M.Caeeiari, A. Contin, G C. Montanari. Use of a Mixed-Weibull Distribution for the Identifieation of PD Phenomena IEEE Transaction on Dieleetrics and Eleetrieal Insulation. 1995 Vol. 2 No. 4614-627

[12]R.Sehifani, R. Candela. A New Algorithm for Mixed Weibull Analysis of partial Diseharge AmPlitude Distributions IEEE Trans On Dieleetrics and Eleetrical Insulation 1999Vo1. 6 No. 2242-249 